\title{
Outcomes following cerebrospinal fluid shunting in high-grade glioma patients
}

\author{
Lorenzo Rinaldo, MD, PhD, Desmond Brown, MD, PhD, Giuseppe Lanzino, MD, and \\ Ian F. Parney, MD, PhD
}

Department of Neurological Surgery, Mayo Clinic, Rochester, Minnesota

OBJECTIVE The clinical course of high-grade central nervous system gliomas is occasionally complicated by hydrocephalus. The risks of shunt placement and clinical outcome following CSF diversion in this population are not well defined.

METHODS The authors retrospectively reviewed the outcomes of patients with pathologically confirmed WHO grade III or IV gliomas with shunt-treated hydrocephalus at their institution. Outcomes of patients in this cohort were compared with those of patients who underwent shunt treatment for normal pressure hydrocephalus (NPH). Hospital-reported outcomes in a national database for malignant primary brain tumor patients undergoing a ventricular shunt procedure were also reviewed.

RESULTS Forty-one patients undergoing CSF shunting between 2001 and 2016 at the authors' institution were identified. Noncommunicating and communicating hydrocephalus occurred at similar rates ( $51.2 \%$ vs $48.8 \%)$. Symptomatic improvement after shunting was observed in $75.0 \%$ of patients. A major complication occurred in $17.1 \%$ of cases, with 2 patients suffering an intracranial hemorrhage. Prior administration of bevacizumab was significantly associated with the incidence of hemorrhage $(p=0.026)$. Three patients $(7.3 \%)$ died during admission, and $8(19.5 \%)$ died within 30 days of shunt placement. The presence of ependymal or leptomeningeal enhancement was more common in patients who died within 30 days $(75.0 \%$ vs $11.1 \%, p=0.001)$. Six patients $(18.1 \%)$ required readmission to the hospital within 30 days of discharge. Revision surgery was necessary in 7 patients $(17.1 \%)$. The median time from shunt placement to death was 150.5 days. In comparison with patients with $\mathrm{NPH}$, shunt-treated high-grade glioma patients had increased in-hospital $(7.3 \%$ vs $0.5 \%, p=0.008)$ and 30 -day $(19.5 \%$ vs $0.8 \%, p<0.001)$ mortality but no difference in the incidence of revision surgery ( $17.1 \%$ vs $17.5 \%, p=0.947)$. Similarly, in the national Vizient Clinical Database Resource Manager, shunt-treated patients with malignant primary brain tumors had an increased length of stay (6.9 vs 3.5 days, $p<0.001$ ), direct cost of admission $(\$ 15,755.80$ vs $\$ 9871.50, p<0.001)$, and 30 -day readmission rates $(20.6 \%$ vs $2.4 \%, p<0.001)$ compared with patients without brain tumors who received a shunt for NPH.

CONCLUSIONS Shunting can be an effective treatment for the symptoms of hydrocephalus in patients with high-grade gliomas. However, the authors' results suggest that this procedure carries a significant risk of complications in this patient population.

https://thejns.org/doi/abs/10.3171/2017.6.JNS17859

KEY WORDS bevacizumab; communicating hydrocephalus; malignant gliomas; mortality; obstructive hydrocephalus; reoperation; ventriculoperitoneal shunt; oncology

$\mathrm{H}$ YDROCEPHALUS, either communicating secondary to impaired CSF resorption or noncommunicating due to obstructive pathology, is a known complication of primary central nervous system high-grade gliomas in the primary central nervous system. ${ }^{1,3,12} \mathrm{CSF}$ diversion in the form of ventricular shunting is an effective therapy for the symptoms of hydrocephalus and may also extend survival in this patient population. ${ }^{1}$ Information on clinical outcomes after shunt treatment in patients with malignant gliomas is limited to small case series, ${ }^{1,3,6,12,15}$ and the risk of complications after shunting, particularly the risk of subsequent revision surgery, is not well-defined in this clinical context. The standard of care for high-grade gliomas currently includes both adjuvant

ABBREVIATIONS CDB/RM = Clinical Database/Resource Manager; ICH = intracranial hemorrhage; $\mathrm{NPH}=$ normal pressure hydrocephalus; $\mathrm{VP}=$ ventriculoperitoneal. SUBMITTED April 4, 2017. ACCEPTED June 19, 2017.

INCLUDE WHEN CITING Published online December 22, 2017; DOI: 10.3171/2017.6.JNS17859. 
radio- and chemotherapy. ${ }^{16}$ In addition, novel antiangiogenic agents, such as bevacizumab, are sometimes used as salvage chemotherapy for progressive disease. ${ }^{5,8}$ It is also not known whether these treatment modalities affect the risks of shunting.

Herein, we reviewed the clinical outcomes of patients with WHO grade III or IV gliomas who developed communicating or obstructive hydrocephalus and were treated with permanent CSF diversion at our institution. We also reviewed outcomes of patients with malignant primary brain tumors admitted for a shunt procedure using a national database of hospital-reported outcomes.

\section{Methods}

\section{Single-Institution Study}

Patient Selection

After receiving approval from the Mayo Clinic institutional review board, we retrospectively reviewed the clinical course and outcomes of patients with malignant gliomas who developed hydrocephalus and were treated with ventricular shunting at Mayo Clinic Rochester between 2001 and 2016. Patients included for analysis harbored histologically confirmed WHO grade III or IV gliomas. Patients with low-grade or nonglial-based tumors were excluded. For a comparison group, we also analyzed the short-term outcomes of patients with normal pressure hydrocephalus (NPH) who were treated with shunting during the same period. Patients with an intracranial mass lesion or a history of intracranial hemorrhage (ICH) were excluded from this group.

\section{Patient Characteristics and Treatment Information}

Collected information on patient characteristics included sex, age at the time of shunt placement, tumor location, WHO grade, type of hydrocephalus, shunt type, shunt valve type, symptoms of hydrocephalus on presentation prior to shunt placement, amount of contrast-enhancing material visualized on brain MRI prior to shunt placement, and presence of either ependymal or leptomeningeal enhancement on brain MRI prior to shunt placement. Tumor location was categorized as either lobar or subcortical. Hydrocephalus type was defined as either communicating or noncommunicating according to standard definitions. Patients with enlarging cystic regions within the resection cavity in the setting of pan-ventriculomegaly were considered to have communicating hydrocephalus. Shunt type was defined by the location of the proximal and distal ends of the shunt catheter, e.g., ventriculoperitoneal (VP), ventriculoatrial, or other, and by the approach to the ventricle, e.g., frontal, parietal, or other. Shunt valves were categorized as either fixed-setting or programmable valves. Symptoms on presentation were categorized into one of 5 groups: focal neurological deficit, headache, cognitive decline, external hydrocephalus, and obtundation. Patients presenting with symptoms in multiple categories were sorted according to their primary and most debilitating symptom. The area of contrast-enhancing material was determined according to the Revised Assessment in Neuro-Oncology (RANO) criteria. ${ }^{17}$ Specifically, perpendicular diameters of enhancing regions measuring at least
$10 \mathrm{~mm}$ were recorded and multiplied together. The sum of the products was then determined to yield a measure of contrast-enhancing area (Fig. 1). In most cases $(n=38)$, the most recent MRI study prior to shunt placement was used to determine the area of contrast enhancement and presence of ependymal or leptomeningeal enhancement. In 3 cases, an MRI study obtained after shunt placement was used to assess these parameters due to lack of a recent MRI study prior to shunting. The mean time from MRI to shunting was 13.6 days (SD 11.1 days), with a range of 0-34 days.

Information on oncological treatment before and after shunt placement included type and date of surgery and history of radio- and chemotherapy. Specific chemotherapeutic regimens received by each patient were also noted. In patients who received bevacizumab prior to shunt placement, the time interval between the last dose and shunt placement was recorded.

\section{Patient Outcomes}

Patient outcomes of interest included incidence of major complications, in-hospital mortality, hospital length of stay in days after shunt placement, incidence of hospital readmission within 30 days of discharge after shunt placement, incidence of mortality within 30 days of shunting, symptomatic improvement in the primary symptom after shunt placement, need for shunt revision surgery, indication for shunt revision surgery, and time to death in days after shunt placement. Symptomatic improvement was assessed subjectively on the patient's first outpatient followup visit after discharge from the hospital.

\section{National Database Study}

\section{Patient Selection}

The Vizient (formerly known as the University HealthSystem Consortium) Clinical Database/Resource Manager $(\mathrm{CDB} / \mathrm{RM})$ is a national database of hospital-reported outcomes. The CDB/RM receives voluntarily submitted administrative billing information on inpatient admissions from more than 270 affiliated institutions across the country. On the basis of this information, the CDB/RM determines and reports mean institutional values for a number of outcomes (e.g., mean length of stay) among patients treated at a given institution. Patients with specific medical conditions are searchable through the use of Medicare Severity-Diagnosis Related Groups as well as International Classification of Diseases, 9th Revision (ICD-9) and International Classification of Diseases, 10th Revision (ICD-10) diagnosis and procedure codes.

Patients admitted for a ventricular shunt procedure in the setting of a preexisting diagnosis of malignant primary brain tumor were included for analysis. Patients admitted for a ventricular shunt procedure were identified by the ventricular shunt procedure Medicare Severity-Diagnosis Related Groups ascribed to patients on admission. Patients with a preexisting diagnosis of a malignant primary brain tumor were identified using ICD-9 codes 191.1, 191.2, 191.3, 191.4, 191.5, 191.5, 191.6, 191.7, 191.8, and 191.9; and ICD-10 codes C711, C712, C713, C714, C715, C716, C717, C718, and C719. Patients who underwent a crani- 


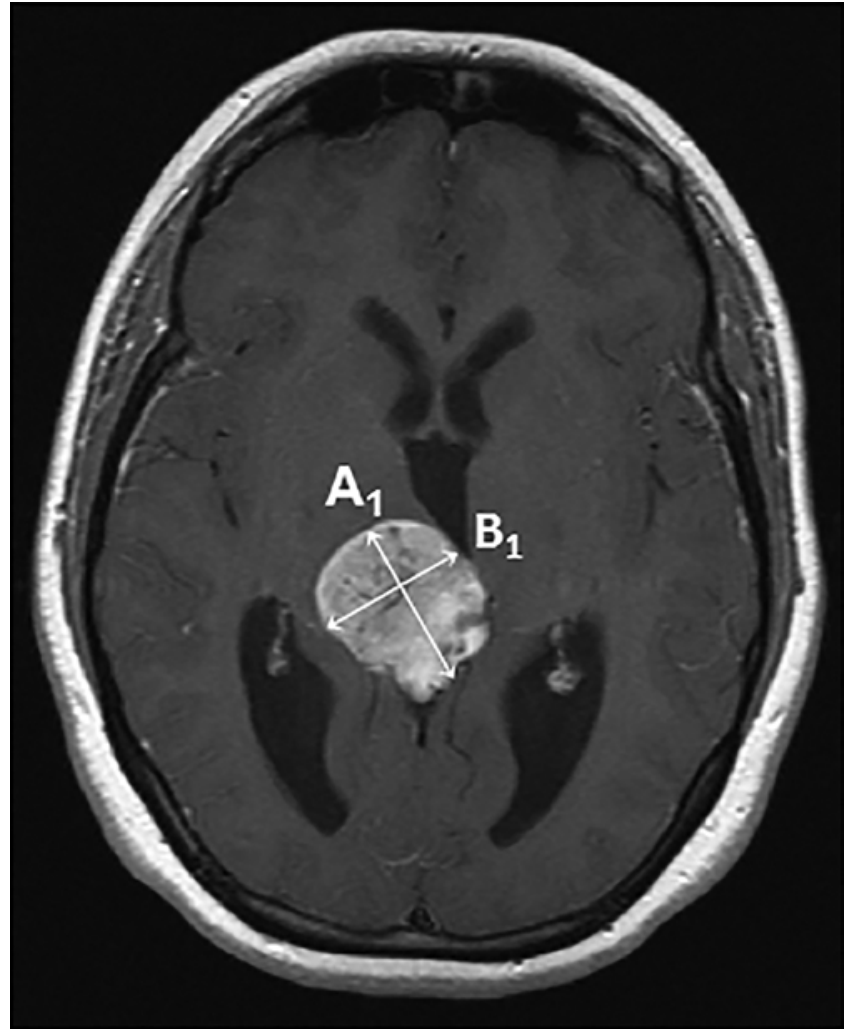

FIG. 1. Representative case demonstrating methodology of measuring contrast-enhancing material. Two perpendicular diameters of at least 10 $\mathrm{mm}$ in length were measured and then multiplied together $\left(A_{1} \times B_{1}\right)$. In cases in which multiple lesions were present, the products of the perpendicular diameters from each lesion were summed $\left(A_{1} \times B_{1}+A_{2} \times B_{2}\right)$.

otomy during the same admission as shunt placement were excluded using ICD-9 codes 01.24, 01.31, 01.51, and 01.59; and ICD-10 codes 009100Z, 00910ZZ, 00C10ZZ, 00C13ZZ，00C14ZZ，00510ZZ，00B10ZZ，00D10ZZ, 00500ZZ, and 00B00ZZ. To exclude pediatric patients with malignant tumors who underwent shunt placement, patients younger than 18 years were also excluded. For a comparison group, patients 18 years and older who underwent a ventricular shunt procedure for the treatment of NPH were identified using ICD-9 and ICD-10 codes 331.5 and G91.2, respectively. Patients with a history of a brain tumor were excluded from this subgroup through the use of the aforementioned ICD-9 and ICD-10 codes for malignant tumors. In addition, patients with a history of a benign brain tumor or brain tumor of uncertain behavior were also excluded from this group using codes 225.0 (ICD-9) and D33.2 (ICD-10), and codes 237.5 (ICD-9) and D43.2 (ICD-10), respectively.

\section{Patient Outcomes}

Patient outcomes of interest included mean length of stay in days, major complication rate, in-hospital mortality rate, 30-day readmission rate, and direct cost of admission. Complications recorded by the CDB/RM include adverse events due to anesthesia; air embolism; aspiration pneumonia; catheter-associated urinary tract infection; central venous catheter-associated bloodstream infection; gastrointestinal hemorrhage; hospital-acquired acute myocardial infarction; hospital-acquired Clostridium difficile colitis; iatrogenic pneumothorax; infection/inflammation due to internal device, implant, or graft; in-hospital stroke; manifestations of poor glycemic control; perioperative pulmonary embolus or deep vein thrombosis; perioperative superficial hemorrhage or hematoma; postoperative infection; postoperative metabolic derangement; postoperative respiratory failure; postoperative sepsis; postoperative shock; postoperative wound dehiscence; and transfusion reaction.

Direct cost of admission refers to the costs attributable to patient care. Direct cost was determined by the CDB/ RM according to the charges administered to a patient during the index admission. Charges were grouped according to their designated revenue code, which is the basis by which charges are determined to be attributable to patient care. For example, a charge with a revenue code for environmental services is not considered related to patient care and thus not counted toward direct cost. The total sum of charges related to patient care was then multiplied by the hospital-specific cost-to-charge ratio available from the institutional Medicare Cost Report. The product is then multiplied by a local wage index to yield direct cost of admission adjusted for regional differences in compensation.

\section{Statistical Analysis}

Descriptive statistics were reported for continuous and categorical variables as the mean and standard deviation and frequency and percentage, respectively. Continuous variables were compared between patient groups using the 2-sample Student t-test, while categorical variables were compared using the Pearson's chi-square test or Fisher's exact test, where appropriate. All statistical tests were 2-sided with an alpha-level for statistical significance set at 0.05 . Analyses were performed using commercially available software (JMP 10.0.0, SAS Institute Inc.).

\section{Results}

\section{Single-Institution Study}

\section{Patient Characteristics and Outcomes After Shunting}

A total of 41 patients met our inclusion criteria for analysis. The complete details of patient characteristics are shown in Table 1. A majority of patients had a highgrade glioma in a lobar versus subcortical location $(68.3 \%$ vs $31.7 \%)$. Twenty-eight patients $(68.3 \%)$ underwent resection, and $13(31.7 \%)$ underwent biopsy only. Among patients who underwent resection, most underwent a single surgery prior to shunt placement $(18 / 41,43.9 \%)$. Eight patients $(19.5 \%)$ underwent 2 resections, and a single patient (2.4\%) had 3 resections prior to shunting. Most patients received chemotherapy $(34 / 41,82.9 \%)$ and radiotherapy $(34 / 41,82.9 \%)$ at some point during their disease course. Among patients who received chemotherapy, all but one were treated with temozolomide. The one patient who did not receive temozolomide was treated with a combination of carboplatin and etoposide. In addition to temozolomide, 8 patients $(19.5 \%)$ received bevacizumab, with 4 patients receiving bevacizumab prior to shunt placement. Three 
TABLE 1. Characteristics of patients undergoing CSF shunting in the setting of high-grade glioma

\begin{tabular}{|c|c|}
\hline Variable & Value \\
\hline Patients, $\mathrm{n}$ & 41 \\
\hline \multicolumn{2}{|l|}{ Sex, $n(\%)$} \\
\hline Female & $15(36.6)$ \\
\hline Male & $26(63.4)$ \\
\hline Age at shunt placement in yrs, mean (SD) & $48.0(14.7)$ \\
\hline \multicolumn{2}{|l|}{ Tumor location, $\mathrm{n}(\%)$} \\
\hline Lobar & $28(68.3)$ \\
\hline Subcortical & $13(31.7)$ \\
\hline \multicolumn{2}{|l|}{ Surgery, n (\%) } \\
\hline Biopsy & $13(31.7)$ \\
\hline Resection & $28(68.3)$ \\
\hline \multicolumn{2}{|l|}{ No. of resections prior to shunting, $n(\%)$} \\
\hline $0^{*}$ & $14(34.1)$ \\
\hline 1 & $18(43.9)$ \\
\hline 2 & $8(19.5)$ \\
\hline 3 & $1(2.4)$ \\
\hline \multicolumn{2}{|l|}{ WHO grade, $n(\%)$} \\
\hline III & $13(31.7)$ \\
\hline IV & $28(68.3)$ \\
\hline \multicolumn{2}{|l|}{ Chemotherapy, n (\%) } \\
\hline Yes & $34(82.9)$ \\
\hline No & 7 (17.1) \\
\hline \multicolumn{2}{|l|}{ Bevacizumab, n (\%) } \\
\hline Yest & $8(19.5)$ \\
\hline No & $33(80.5)$ \\
\hline \multicolumn{2}{|l|}{ Radiation therapy, n (\%) } \\
\hline Yes & $34(82.9)$ \\
\hline No & 7 (17.1) \\
\hline \multicolumn{2}{|l|}{ Treatment preceded hydrocephalus, $\mathrm{n}(\%)$} \\
\hline Yes & $22(53.7)$ \\
\hline No & $19(46.3)$ \\
\hline \multicolumn{2}{|l|}{ Hydrocephalus, n (\%) } \\
\hline Communicating & $20(48.8)$ \\
\hline Noncommunicating & $21(51.2)$ \\
\hline Area of contrast enhancement in $\mathrm{mm}^{2}$, mean (SD) & $969.1(984.7)$ \\
\hline Range & 0.0 to 3421.8 \\
\hline \multicolumn{2}{|l|}{ Ependymal or leptomeningeal enhancement, $\mathrm{n}(\%)$} \\
\hline Yes & $11(26.8)$ \\
\hline No & $30(73.2)$ \\
\hline \multicolumn{2}{|l|}{ CSF cytology for abnormal cells, $n$ (\%) $\ddagger$} \\
\hline Positive & $1(9.0)$ \\
\hline Negative & $10(91.0)$ \\
\hline Time from op to shunting in days, mean (SD) & $145.5(296.0)$ \\
\hline Range & $(-720$ to 1087$)$ \\
\hline \multicolumn{2}{|l|}{ Approach, n (\%) } \\
\hline Frontal & $18(41.5)$ \\
\hline Parietal & $17(43.9)$ \\
\hline Other & $6(14.6)$ \\
\hline
\end{tabular}

CONTINUED IN NEXT COLUMN
》 CONTINUED FROM PREVIOUS COLUMN

TABLE 1. Characteristics of patients undergoing CSF shunting in the setting of high-grade glioma

\begin{tabular}{|c|c|}
\hline Variable & Value \\
\hline \multicolumn{2}{|l|}{ Valve type, n (\%) } \\
\hline Fixed setting & $37(90.2)$ \\
\hline Programmable & $4(9.8)$ \\
\hline \multicolumn{2}{|l|}{ Antibiotic-impregnated catheter, $\mathrm{n}(\%) \S$} \\
\hline Yes & $1(2.6)$ \\
\hline No & $38(97.4)$ \\
\hline \multicolumn{2}{|l|}{ Symptom at presentation, $\mathrm{n}(\%)$} \\
\hline Obtundation & $7(17.0)$ \\
\hline Neurological deficit & $7(17.0)$ \\
\hline Headache & $9(22.0)$ \\
\hline External hydrocephalus & $6(14.6)$ \\
\hline Cognitive decline & $12(29.3)$ \\
\hline Length of stay in days, mean (SD) & $5.4(4.3)$ \\
\hline Major complication, $\mathrm{n}(\%)$ & $7(17.1)$ \\
\hline Seizures & $3(42.8)$ \\
\hline $\mathrm{ICH}$ & $2(28.6)$ \\
\hline DVT & $1(14.3)$ \\
\hline Sepsis & $1(14.3)$ \\
\hline In-hospital mortality, n (\%) & $3(7.3)$ \\
\hline 30-day mortality, n (\%) & $8(19.5)$ \\
\hline Readmission w/in 30 days, $\mathrm{n}(\%) \uparrow$ & $6(18.1)$ \\
\hline \multicolumn{2}{|l|}{ Shunt revision surgery } \\
\hline Yes & $7(17.1)$ \\
\hline No & $34(82.9)$ \\
\hline \multicolumn{2}{|l|}{ Time from shunting to death (days) ${ }^{* *}$} \\
\hline Mean (SD) & $248.7(336.5)$ \\
\hline Median & 150.5 \\
\hline Range & (5 to 1741) \\
\hline \multicolumn{2}{|c|}{$\begin{array}{l}\text { DVT = deep vein thrombosis. } \\
\text { * Includes patients who underwent stereotactic biopsy prior to shunting. } \\
\dagger \text { Only } 4 \text { patients received bevacizumab prior to shunt placement. } \\
\text { ‡ CSF cytology prior to shunting was performed on only } 11 \text { of } 41 \text { patients. } \\
\S \text { Information on type of ventricular catheter was not available in } 2 \text { patients. } \\
\text { I Excludes patients who died during hospitalization or within } 30 \text { days of shunt } \\
\text { placement. } \\
\text { ** Two patients were living at the time of analysis. }\end{array}$} \\
\hline
\end{tabular}

patients received lomustine in addition to temozolomide and bevacizumab, while a single patient received a combination of temozolomide and lomustine. Finally, there were 2 patients who received a combination of temozolomide and CPT-11. A slight majority of patients developed hydrocephalus after receiving adjunctive therapy $(53.7 \%$ vs $46.3 \%)$.

The mean time from initial surgery to shunt treatment was 145.5 days, with a range of -720 to 1087 days. All patients who underwent shunt placement prior to surgery (n =3) presented with symptoms of obstructive hydrocephalus due to a subcortically located high-grade glioma. Each of these patients underwent either a diagnostic biopsy or 
TABLE 2. Likelihood of symptom improvement

\begin{tabular}{llc}
\hline \multicolumn{1}{c}{ Variable } & Value & p Value \\
\hline Symptomatic improvement, $\mathrm{n}(\%)^{*}$ & & \\
\hline Yes & $27(75.0)$ & \\
\hline No & $9(25.0)$ & \\
\hline Symptom at presentation, $\mathrm{n}(\%) \dagger$ & & 0.367 \\
\hline Obtundation & $5(71.4)$ & \\
\hline Neurological deficit & $2(50.0)$ & \\
\hline Headache & $8(100.0)$ \\
\hline External hydrocephalus & $4(66.8)$ \\
\hline Cognitive decline & $8(72.7)$ \\
\hline
\end{tabular}

* Assessed only for patients with at least 1 follow-up visit after discharge. $\dagger$ Values represent the number of patients experiencing improvement from the time of presentation.

subtotal resection after shunting. Patient symptomatology secondary to hydrocephalus included obtundation (17.0\%), neurological deficit $(17.0 \%)$, headache $(22.0 \%)$, external hydrocephalus (14.6\%), and cognitive decline (29.3\%). A majority of patients were treated with VP shunt placement $(80.4 \%)$. There were 3 patients in whom a shunt was placed in an enlarging resection cavity cyst (7.3\%), while 4 patients had a shunt placed in the subgaleal (2/4), epidural (1/4), or subdural space (1/4). In all of these patients, the distal end of the shunt was placed in the peritoneum. A single patient $(2.4 \%)$ was treated with a ventriculoatrial shunt. For patients receiving a VP or ventriculoatrial shunt, the ventricle was accessed through a frontal approach in 18 patients and through a parietal approach in 17 patients. A majority of patients received a fixed-setting valve $(37 / 41,90.2 \%)$, with only 4 patients $(9.8 \%)$ receiving a programmable valve. An antibiotic-impregnated ventricular catheter was used in a single patient (2.4\%).

The mean area of contrast-enhancing material on MRI prior to shunting was $969.1 \mathrm{~mm}^{2}$. Evidence of ependymal or leptomeningeal enhancement was present in 11 patients (26.8\%). Cytological studies on CSF obtained prior to shunting were performed in only 11 patients, the findings of which were negative for presence of malignant cells in all but one patient.

The mean length of stay after shunt placement was 5.4 days. Seven patients $(17.1 \%)$ experienced a major complication during their admission, with 2 patients $(4.9 \%)$ suffering an ICH, one of which was ultimately fatal during that patient's hospital admission. Overall, 3 patients (7.3\%) died during their admission. The mortality rate within 30 days of shunting was $19.5 \%$ (8/41). Six patients (18.1\%) required readmission to a hospital setting within 30 days of discharge after undergoing shunt placement. Seven patients ultimately required shunt revision surgery, 4 of whom experienced a shunt malfunction and 3 experienced a shunt infection (Table 1). The mean and median times from shunting to death were 248.7 and 150.5 days, respectively.

After discharge, 27 patients experienced improvement in their primary symptom at presentation prior to shunting. Headache was the most likely symptom to improve $(8 / 8,100.0 \%)$, new neurological deficit was least likely to
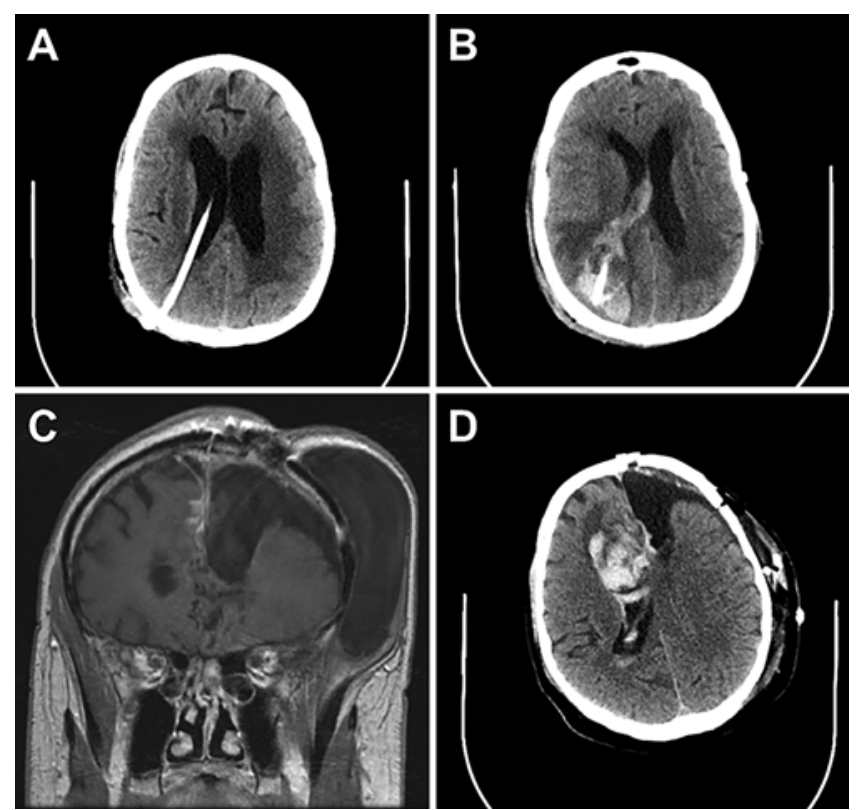

FIG. 2. Cases of shunting complicated by ICH. A: Postoperative head CT scan obtained after placement of a VP shunt. B: Head CT scan obtained after clinical deterioration, demonstrating hemorrhage 1 week after shunt insertion. C: Preoperative MR image obtained in another patient, demonstrating a subgaleal fluid collection communicating with the resection cavity and left lateral ventricle. D: Postoperative CT scan demonstrating hemorrhage after placement of a subgaleal-peritoneal shunt.

improve $(2 / 4,50.0 \%)$. The frequency of improvement after shunting for each presenting symptom is detailed in Table 2.

\section{Effect of Prior Chemotherapy or Radiotherapy on the Incidence} of ICH After Shunting

We then examined whether a history of prior chemo-

TABLE 3. Effect of chemo- or radiotherapy on incidence of ICH after shunting

\begin{tabular}{lccc}
\hline \multicolumn{1}{c}{ Variable } & No ICH $(\mathrm{n}=21)$ & $\mathrm{ICH}(\mathrm{n}=2)$ & $\mathrm{p} \mathrm{Value}^{*}$ \\
\hline Chemotherapy & & & 0.511 \\
\hline Yes & $32(94.1)$ & $2(5.9)$ & \\
\hline No & $7(100.0)$ & $0(0.0)$ & \\
\hline Radiation therapy & & & 0.999 \\
\hline Yes & $32(94.1)$ & $2(5.9)$ & \\
\hline No & $7(100.0)$ & $0(0.0)$ & \\
\hline $\begin{array}{l}\text { Bevacizumab } \\
\text { Yes }\end{array}$ & $6(75.0)$ & $2(25.0)$ & \\
\hline No & $33(100.0)$ & $0(0.0)$ & \\
\hline $\begin{array}{l}\text { Bevacizumab pre-shunt } \\
\text { placement }\end{array}$ & & & 0.026 \\
\hline Yes & $2(50.0)$ & $2(50.0)$ & \\
\hline No & $18(100.0)$ & $0(0.0)$ & \\
\hline Boctace
\end{tabular}

Boldface type indicates statistical significance.

* Comparisons performed using Fisher's exact test. 
TABLE 4. Comparison of patients with communicating and noncommunicating hydrocephalus

\begin{tabular}{|c|c|c|c|}
\hline Variable & Communicating $(n=20)$ & Noncommunicating $(n=21)$ & $p$ Value \\
\hline Age at shunt placement in yrs, mean (SD) & $50.4(15.7)$ & $45.7(13.7)$ & 0.310 \\
\hline Sex, $n(\%)$ & & & 0.275 \\
\hline Female & $9(45.0)$ & $6(28.6)$ & \\
\hline Male & $11(55.0)$ & $15(71.4)$ & \\
\hline Tumor location, $n(\%)$ & & & $<0.001^{*}$ \\
\hline Lobar & $20(100.0)$ & $8(38.1)$ & \\
\hline Subcortical & $0(0.0)$ & $13(61.9)$ & \\
\hline Surgery, n (\%) & & & $0.043^{*}$ \\
\hline Biopsy & $3(15.0)$ & $10(47.6)$ & \\
\hline Resection & $17(85.0)$ & $11(52.4)$ & \\
\hline No. of resections prior to shunting, $n(\%)$ & & & $0.009^{*}$ \\
\hline$\leq 1$ & $12(60.0)$ & $20(95.2)$ & \\
\hline$>1$ & $8(40.0)$ & $1(4.8)$ & \\
\hline WHO grade, $n(\%)$ & & & 0.658 \\
\hline III & $7(35.0)$ & $6(28.6)$ & \\
\hline IV & $13(65.0)$ & $15(71.4)$ & \\
\hline Area of contrast enhancement in $\mathrm{mm}^{2}$, mean (SD) & $826.3(1019.0)$ & $1098.4(958.8)$ & 0.390 \\
\hline Range & (0.0 to 3224.4$)$ & (0.0 to 3421.8$)$ & \\
\hline Ependymal or leptomeningeal enhancement, $\mathrm{n}(\%)$ & & & $0.306^{*}$ \\
\hline Yes & $7(35.0)$ & $4(19.1)$ & \\
\hline No & $13(65.0)$ & $17(80.9)$ & \\
\hline CSF cytology for abnormal cells, $n(\%) \dagger$ & & & $0.999^{*}$ \\
\hline Positive & $1(14.3)$ & $0(0.0)$ & \\
\hline Negative & $6(85.7)$ & $4(100.0)$ & \\
\hline Treatment preceded hydrocephalus, $n(\%)$ & & & $<0.001^{*}$ \\
\hline Yes & $18(90.0)$ & $4(20.0)$ & \\
\hline No & $2(10.0)$ & $16(80.0)$ & \\
\hline Time from op to shunting in days, mean (SD) & $215.1(242.7)$ & $79.2(331.4)$ & 0.144 \\
\hline Range & (8 to 988) & $(-720$ to 1087$)$ & \\
\hline Symptom at presentation, $\mathrm{n}(\%)$ & & & 0.012 \\
\hline Obtundation & $1(5.0)$ & $6(28.6)$ & \\
\hline Neurological deficit & $4(20.0)$ & $3(14.3)$ & \\
\hline Headache & $2(10.0)$ & $7(33.3)$ & \\
\hline External hydrocephalus & $6(30.0$ & $0(0.0)$ & \\
\hline Cognitive decline & $7(35.0)$ & $5(23.8)$ & \\
\hline Symptomatic improvement, n (\%) & & & $0.706^{*}$ \\
\hline Yes & $12(70.6)$ & $15(79.0)$ & \\
\hline No & $5(29.4)$ & $4(21.0)$ & \\
\hline Major complication, n (\%) & & & $0.238^{*}$ \\
\hline Yes & $5(25.0)$ & $2(9.5)$ & \\
\hline No & $15(75.0)$ & $19(90.5)$ & \\
\hline In-hospital mortality, n (\%) & & & $0.606^{*}$ \\
\hline Yes & $2(10.0)$ & $1(4.8)$ & \\
\hline No & $18(90.0)$ & $20(95.2)$ & \\
\hline 30-day mortality, n (\%) & & & $0.999^{*}$ \\
\hline Yes & $4(20.0)$ & $4(19.1)$ & \\
\hline No & $16(80.0)$ & $17(80.9)$ & \\
\hline
\end{tabular}


» CONTINUED FROM PAGE 989

TABLE 4. Comparison of patients with communicating and noncommunicating hydrocephalus

\begin{tabular}{lccc}
\hline \multicolumn{1}{c}{ Variable } & Communicating $(\mathrm{n}=20)$ & Noncommunicating $(\mathrm{n}=21)$ & $\mathrm{p}$ Value \\
\hline Readmission w/in 30 days, $\mathrm{n}(\%) \ddagger$ & $3(18.8)$ & $3(17.7)$ & $0.999^{*}$ \\
\hline Yes & $13(81.2)$ & $14(82.3)$ & $271.9(413.9)$ \\
\hline No & $225.6(245.7)$ & & 0.677 \\
\hline Time from shunting to death in days, mean (SD) & & & \\
\hline${ }^{*}$ Comparison made using Fisher's exact test. & & \\
$\dagger$ CSF cytology prior to shunting was performed in only 11 of 41 patients. & \\
$\ddagger$ Excludes patients who died during hospitalization or within 30 days of shunt placement. &
\end{tabular}

or radiotherapy had an effect on the incidence of $\mathrm{ICH}$ after shunting. Two patients experienced a hemorrhage after shunting. The first patient tolerated placement of a VP shunt from a parietal approach without any immediate complications. Prior to anticipated discharge approximately 1 week later, the patient resumed receiving an anticoagulant due to a previous history of a deep venous thrombosis. Shortly after receiving the first dose, the patient experienced obtundation. A head CT scan was obtained that demonstrated a large hemorrhage along the shunt track (Fig. 2A and B). Comfort measures were instituted, and the patient died shortly thereafter. The second patient underwent placement of a subgaleal-peritoneal shunt for an enlarging subgaleal fluid collection that was in communication with the tumor resection cavity and ventricular system (Fig. 2C). Postoperatively, the patient did not return to his previous mental baseline, and a head CT scan demonstrated a large hemorrhage contralateral to the side of shunt insertion (Fig. 2D). The patient was managed conservatively and ultimately recovered, allowing eventual discharge from the hospital.

Both patients who experienced hemorrhage had previously received both radiation therapy and chemotherapy. These patients were also among the 4 who had received bevacizumab prior to shunting, yielding a hemorrhage rate of $50.0 \%$ for this subgroup of patients. The first patient had last received bevacizumab 29 days prior to the shunt procedure, whereas the second patient received the last dose of bevacizumab 16 days prior to shunting. Of the 2 patients who did not experience hemorrhage, one had received bevacizumab only 9 days prior to surgery, and information on the date of last bevacizumab dose was not available for the other patient. Bevacizumab administration was found to be significantly associated with the incidence of ICH among patients who received adjunctive therapy prior to shunting $(50.0 \%$ vs $0.0 \%, \mathrm{p}=0.0260)$. The association of bevacizumab administration with hemorrhage persisted when analysis was expanded to include all patients regardless of timing of bevacizumab with respect to shunting ( $25.0 \%$ vs $0.0 \%, \mathrm{p}=0.034$; Table 3$)$.

\section{Comparison of Patients With Communicating and Noncommunicating Hydrocephalus}

The proportion of patients who developed communicating versus noncommunicating hydrocephalus was roughly even (48.8\% vs $51.2 \%)$. Patients with noncommunicating hydrocephalus were more likely to have their tumor located in a subcortical location $(61.9 \%$ vs $0.0 \%, \mathrm{p}$ $<0.001)$ and to undergo a biopsy only ( $47.6 \%$ vs $15.0 \%$, p $=0.043$ ) than patients with communicating hydrocephalus. More than one resection prior to shunt placement was more common in patients with communicating hydrocephalus $(4.8 \%$ [noncommunicating hydrocephalus] vs $40.0 \%, \mathrm{p}=0.009$ ), as was a history of adjunctive chemoor radiotherapy prior to shunting $(20.0 \%$ [noncommunicating hydrocephalus] vs $90.0 \%, \mathrm{p}<0.001)$. There were significant differences in the frequency of predominant presenting symptoms between patients with communicating and noncommunicating hydrocephalus (Table 4), although there was no difference in the frequency of symptomatic improvement after shunting between these groups $(70.6 \%$ vs $79.0 \%, p=0.706)$. There were no significant differences in the incidence of major complications ( $25.0 \%$ vs $9.5 \%, \mathrm{p}=0.238)$, in-hospital mortality $(10.0 \%$ vs $4.8 \%, \mathrm{p}=0.606), 30$-day mortality $(20.0 \%$ vs $19.1 \%$, p $=0.999)$, or readmission within 30 days $(18.8 \%$ vs $17.7 \%$, $\mathrm{p}=0.999$ ) between patients with communicating and noncommunicating hydrocephalus.

\section{Comparison of Patients Who Did and Did Not Undergo Shunt Revision}

We also compared patient and treatment characteristics between patients who did and did not require shunt revision surgery, the results of which are listed in Table 5. There were no significant differences between these groups. There were no significant differences in frequency of revision in patients with subcortical tumors $(57.1 \%$ vs $26.5 \%, \mathrm{p}=0.181)$ or those treated with a biopsy $(57.1 \%$ vs $26.5 \%, \mathrm{p}=0.181)$. The proportion of patients who underwent more than one resection was not statistically different between patients who did and did not undergo revision $(42.9 \%$ vs $17.6 \%, \mathrm{p}=0.165)$. There was no difference in the incidence of revision between patients with communicating versus noncommunicating hydrocephalus $(42.9 \%$ vs $57.1 \%, p=0.999)$. Finally, revision surgery was more common among patients who had not yet received adjunctive therapy $(71.4 \%$ vs $60.6 \%, p=0.219)$, although this difference was also not significant.

\section{Comparison of Patients With Malignant Gliomas and NPH}

Outcomes of patients with malignant gliomas treated with shunting were then compared with those of patients undergoing shunt treatment for NPH. There were 366 patients with NPH who underwent placement of a ventricu- 
TABLE 5. Comparison of patients who did and did not undergo shunt revision

\begin{tabular}{|c|c|c|c|}
\hline Variable & No Revision $(n=34)$ & Revision $(n=7)$ & p Value* \\
\hline Age at shunt placement in yrs, mean (SD) & $48.6(15.5)$ & $45.1(10.9)$ & 0.583 \\
\hline Sex, $n(\%)$ & & & 0.693 \\
\hline Female & $12(35.3)$ & $3(42.9)$ & \\
\hline Male & $22(64.7)$ & $4(57.1)$ & \\
\hline Tumor location, $\mathrm{n}(\%)$ & & & 0.181 \\
\hline Lobar & $25(73.5)$ & $3(42.9)$ & \\
\hline Subcortical & $9(26.5)$ & $4(57.1)$ & \\
\hline Surgery, n (\%) & & & 0.181 \\
\hline Biopsy & $9(26.5)$ & $4(57.1)$ & \\
\hline Resection & $25(73.5)$ & $3(42.9)$ & \\
\hline No. of resections prior to shunting, $n(\%)$ & & & 0.165 \\
\hline$\leq 1$ & $28(82.4)$ & $4(57.1)$ & \\
\hline$>1$ & $6(17.6)$ & $3(42.9)$ & \\
\hline WHO grade, $n(\%)$ & & & 0.999 \\
\hline III & $11(32.4)$ & $2(28.6)$ & \\
\hline IV & $23(67.6)$ & $5(71.4)$ & \\
\hline Area of contrast enhancement in $\mathrm{mm}^{2},(\mathrm{SD})$ & $1006.1(1020.9)$ & $794.8(837.6)$ & \\
\hline Range & (0.0 to 3421.8$)$ & (0.0 to 2495.2$)$ & 0.613 \\
\hline Ependymal or leptomeningeal enhancement, $n$ (\%) & & & 0.160 \\
\hline Yes & $23(67.3)$ & $7(100.0)$ & \\
\hline No & $11(32.4)$ & $0(0.0)$ & \\
\hline CSF cytology for abnormal cells, $n(\%) \dagger$ & & & 0.999 \\
\hline Positive & $1(10.0)$ & $0(0.0)$ & \\
\hline Negative & $9(90.0)$ & $1(100.0)$ & \\
\hline Hydrocephalus & & & 0.999 \\
\hline Communicating & $17(50.0)$ & $3(42.9)$ & \\
\hline Noncommunicating & $17(50.0)$ & $4(57.1)$ & \\
\hline Chemotherapy, n (\%) & & & 0.321 \\
\hline Yes & $7(20.6)$ & $7(100.0)$ & \\
\hline No & $27(79.4)$ & $0(0.0)$ & \\
\hline Bevacizumab, n (\%) & & & 0.606 \\
\hline Yes & $6(17.7)$ & $2(28.6)$ & \\
\hline No & $28(82.3)$ & $5(71.4)$ & \\
\hline Radiation therapy, n (\%) & & & 0.321 \\
\hline Yes & $7(20.6)$ & $7(100.0)$ & \\
\hline No & $27(79.4)$ & $0(0.0)$ & \\
\hline Treatment preceded hydrocephalus, $n(\%)$ & & & 0.219 \\
\hline Yes & $13(39.4)$ & $2(28.6)$ & \\
\hline No & $20(60.6)$ & $5(71.4)$ & \\
\hline Time from op to shunting in days, mean (SD) & $171.4(319.5)$ & $19.4(23.9)$ & 0.220 \\
\hline Range & $(-720$ to 1087$)$ & $(-5$ to 64$)$ & \\
\hline Approach, n (\%) & & & 0.228 \\
\hline Frontal & $14(41.2)$ & $4(57.1)$ & \\
\hline Parietal & $16(47.1)$ & $1(14.3)$ & \\
\hline Other & $4(11.8)$ & $2(28.6)$ & \\
\hline \multicolumn{4}{|l|}{ Valve type, $\mathrm{n}(\%)$} \\
\hline Fixed setting & $30(90.9)$ & $6(85.7)$ & \\
\hline Programmable & $3(9.1)$ & $1(14.3)$ & 0.552 \\
\hline
\end{tabular}


» CONTINUED FROM PAGE 991

TABLE 5. Comparison of patients who did and did not undergo shunt revision

\begin{tabular}{|c|c|c|c|}
\hline Variable & No Revision $(n=34)$ & Revision ( $n=7$ ) & p Value* \\
\hline Antibiotic-impregnated catheter, $\mathrm{n}(\%) \ddagger$ & & & 0.636 \\
\hline Yes & $31(96.9)$ & $7(100.0)$ & \\
\hline No & $1(3.1)$ & $0(0.0)$ & \\
\hline
\end{tabular}

lar shunt during the study period. Patients with malignant gliomas were significantly younger than those with NPH (48.0 vs 72.4 years, $p<0.001$ ). Both the incidence of inhospital $(7.3 \%$ vs $0.5 \%, \mathrm{p}=0.008)$ and 30 -day $(19.5 \%$ vs $0.8 \%, \mathrm{p}<0.001)$ mortality were significantly greater in patients with gliomas. There was a trend toward increased frequency of 30-day readmission in patients with highgrade gliomas $(18.1 \%$ vs $8.5 \%, \mathrm{p}=0.068)$; however, this difference was not statistically significant. There was no difference in the rate of revision surgery between these 2 groups $(17.1 \%$ vs $17.5 \%, \mathrm{p}=0.947)$. While the average

TABLE 6. Comparison of outcomes after shunting between patients with malignant gliomas and with $\mathrm{NPH}$

\begin{tabular}{|c|c|c|c|}
\hline Variable & Glioma $(n=41)$ & $\mathrm{NPH}(\mathrm{n}=366)$ & $p$ Value \\
\hline $\begin{array}{l}\text { Age at shunt placement in } \\
\text { yrs, mean (SD) }\end{array}$ & $48.0(14.7)$ & $72.4(10.4)$ & $<0.001$ \\
\hline Sex, $n(\%)$ & & & 0.970 \\
\hline Female & $15(36.6)$ & $135(36.9)$ & \\
\hline Male & $26(63.4)$ & $231(63.1)$ & \\
\hline $\mathrm{ICH}, \mathrm{n}(\%)$ & & & $0.150 \dagger$ \\
\hline Yes & $2(4.9)$ & $5(1.4)$ & \\
\hline No & $39(95.1)$ & $361(98.6)$ & \\
\hline In-hospital mortality, n (\%) & & & $0.008 \dagger$ \\
\hline Yes & $3(7.3)$ & $2(0.5)$ & \\
\hline No & $15(75.0)$ & $364(99.5)$ & \\
\hline 30-day mortality, n (\%) & & & $<0.001 \uparrow$ \\
\hline Yes & $8(19.5)$ & $3(0.8)$ & \\
\hline No & $33(80.5)$ & $363(99.2)$ & \\
\hline 30-day readmission, $\mathrm{n}(\%)^{*}$ & & & 0.068 \\
\hline Yes & $6(18.1)$ & $31(8.5)$ & \\
\hline No & 27 (81.8) & $332(91.5)$ & \\
\hline Revision surgery & & & 0.947 \\
\hline Yes & 7 (17.1) & $64(17.5)$ & \\
\hline No & $34(82.9)$ & $302(82.5)$ & \\
\hline $\begin{array}{l}\text { Time to revision in days, } \\
\text { mean (SD) }\end{array}$ & $77.9(77.5)$ & $521.4(877.3)$ & 0.188 \\
\hline Range & (12 to 193 ) & (0 to 3402 ) & \\
\hline
\end{tabular}

time to revision was greater in patients with NPH $(77.9$ vs 521.4 days, $\mathrm{p}=0.178)$, this difference was also not significant. The results of all comparisons made between patients with high-grade gliomas and NPH are presented in Table 6.

\section{Comparison of Patients With Up to 30-Day and At Least 90-Day} Survival

We then compared clinical and imaging characteristics of patients who died 30 days or less after shunt placement with those of patients surviving at least 90 days after shunting. Eight patients died within the 30-day postoperative period, while 27 patients survived for at least 90 days. Evidence of ependymal or leptomeningeal enhancement was more common in patients surviving less than 30
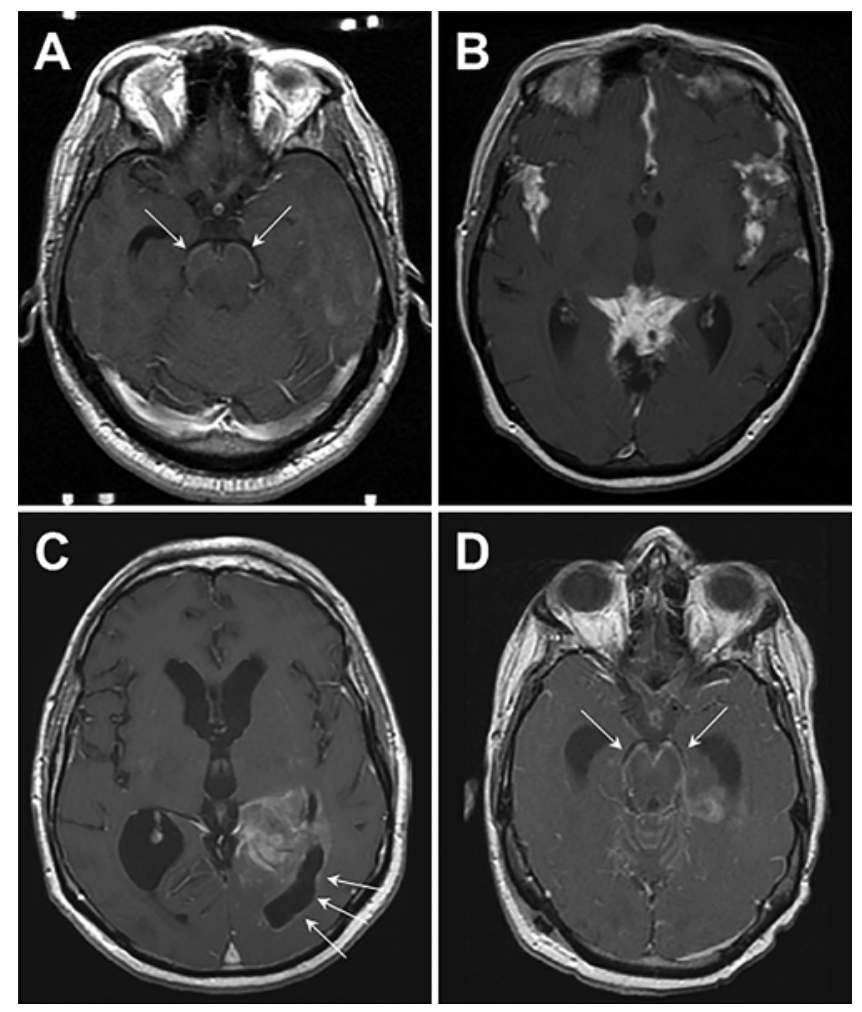

FIG. 3. Representative examples of patients with ependymal or leptomeningeal enhancement are shown in panels A-D. Arrows denote areas of enhancement in panels $\mathrm{A}, \mathrm{C}$, and $\mathrm{D}$. 
TABLE 7. Comparison of patients with up to 30 -day and at least 90 -day survival

\begin{tabular}{|c|c|c|c|}
\hline Variable & $\leq 30$-Day Survival $(n=8)$ & $\geq 90$-Day Survival $(n=27)$ & $p$ Value* \\
\hline Age at shunt placement in yrs, mean (SD) & $44.0(15.4)$ & $46.7(13.7)$ & 0.632 \\
\hline Sex, $n(\%)$ & & & 0.108 \\
\hline Female & $1(12.5)$ & $13(48.2)$ & \\
\hline Male & $7(87.5)$ & $14(51.8)$ & \\
\hline Tumor location, $\mathrm{n}(\%)$ & & & 0.999 \\
\hline Lobar & $5(62.5)$ & $17(63.0)$ & \\
\hline Subcortical & $3(37.5)$ & $10(37.0)$ & \\
\hline Surgery, n (\%) & & & 0.686 \\
\hline Biopsy & $3(37.5)$ & $8(29.6)$ & \\
\hline Resection & $5(62.5)$ & $19(70.4)$ & \\
\hline No. of resections prior to shunting, $n(\%)$ & & & 0.958 \\
\hline$\leq 1$ & $6(75.0)$ & $20(74.1)$ & \\
\hline$>1$ & $2(25.0)$ & $7(25.9)$ & \\
\hline WHO grade, $\mathrm{n}(\%)$ & & & 0.077 \\
\hline III & $5(62.5)$ & $6(22.2)$ & \\
\hline IV & $3(37.5)$ & $21(77.8)$ & \\
\hline Area of contrast enhancement in $\mathrm{mm}^{2}$, mean (SD) & $787.7(832.3)$ & $958.0(909.2)$ & 0.657 \\
\hline Range & (0.0 to 2312.3$)$ & (0.0 to 3224.4$)$ & \\
\hline Ependymal or leptomeningeal enhancement, n (\%) & & & 0.001 \\
\hline Yes & $6(75.0)$ & $3(11.1)$ & \\
\hline No & $2(25.0)$ & $24(88.9)$ & \\
\hline CSF cytology for abnormal cells, $\mathrm{n}(\%) \dagger$ & & & 0.375 \\
\hline Positive & $1(33.3)$ & $0(0.0)$ & \\
\hline Negative & $2(66.7)$ & $5(100.0)$ & \\
\hline Chemotherapy, n (\%) & & & 0.030 \\
\hline Yes & $5(62.5)$ & $26(96.3)$ & \\
\hline No & $3(37.5)$ & $1(3.7)$ & \\
\hline Bevacizumab, n (\%) & & & 0.648 \\
\hline Yest & $2(25.0)$ & $5(18.5)$ & \\
\hline No & $6(75.0)$ & $22(81.5)$ & \\
\hline Radiation therapy, n (\%) & & & 0.067 \\
\hline Yes & $5(62.5)$ & $25(92.6)$ & \\
\hline No & $3(37.5)$ & $2(7.4)$ & \\
\hline Treatment preceded hydrocephalus, $n(\%)$ & & & 0.672 \\
\hline Yes & $5(71.4)$ & $15(55.6)$ & \\
\hline No & $2(28.6)$ & $12(44.4)$ & \\
\hline Hydrocephalus, n (\%) & & & 0.999 \\
\hline Communicating & $4(50.0)$ & $14(51.9)$ & \\
\hline Noncommunicating & $4(50.0)$ & $13(48.1)$ & \\
\hline Time from op to shunting in days, mean (SD) & $310.3(356.9)$ & $88.1(272.2)$ & 0.068 \\
\hline Range & (0 to 988$)$ & $(-720$ to 1087$)$ & \\
\hline Approach, n (\%) & & & 0.410 \\
\hline Frontal & $4(50.0)$ & $12(44.5)$ & \\
\hline Parietal & $4(50.0)$ & $10(37.0)$ & \\
\hline Other & $0(0.0)$ & $5(18.5)$ & \\
\hline Valve type, $\mathrm{n}(\%)$ & & & 0.552 \\
\hline Fixed setting & $8(100.0)$ & $22(84.6)$ & \\
\hline Programmable & $0(0.0)$ & $4(15.4)$ & \\
\hline
\end{tabular}


" CONTINUED FROM PAGE 993

TABLE 7. Comparison of patients with up to 30 -day and at least 90 -day survival

\begin{tabular}{lccc}
\hline \multicolumn{1}{c}{ Variable } & $\leq 30$-Day Survival $(n=8)$ & $\geq 90$-Day Survival $(n=27)$ & $p$ Value* \\
\hline Antibiotic-impregnated catheter, $n(\%) \ddagger$ & & & 1.000 \\
\hline Yes & $0(0.0)$ & $0(0.0)$ & \\
\hline No & $8(100.00)$ & & 0.312 \\
\hline Major complication, $n(\%)$ & $3(100.0)$ & $4(14.8)$ \\
\hline Yes & $5(62.5)$ & $23(85.2)$ & \\
\hline No & & & \\
\hline${ }^{*}$ Comparison made using Fisher's exact test. & & \\
$\dagger$ CSF cytology prior to shunting was performed on only 11 of 41 patients & \\
$\ddagger$ Information on type of ventricular catheter was not available in 2 patients.
\end{tabular}

days $(75.0 \%$ vs $11.1 \%, \mathrm{p}=0.001)$. Representative images of ependymal or leptomeningeal enhancement are displayed in Fig. 3. There was no difference in the area of residual contrast-enhancing tumor in patients with $\leq 30$ - and $\geq 90$ day survival (787.7 vs $958.0 \mathrm{~mm}^{2}, \mathrm{p}=0.657$ ). Administration of chemotherapy was less common in patients with $\leq 30$-day survival $(62.5 \%$ vs $96.3 \%, p=0.030)$. The results of all comparisons between patients with $\leq 30$ - and $\geq 90$ day survival are presented in Table 7.

\section{National Database Study}

There were 60 institutions that reported the outcomes of 112 patients with a malignant primary brain tumor who received a ventricular shunt. As a comparison group, 140 institutions reported the outcomes of 4251 patients without a brain tumor who underwent a shunt procedure for treatment of NPH. Length of stay was significantly longer in patients with a brain tumor $(6.9$ vs 3.5 days, $\mathrm{p}<0.001)$. There were no differences in the rate of complications $(6.7 \%$ vs $2.8 \%, p=0.054)$ or mortality $(1.2 \%$ vs $0.2 \%, p$ $=0.104$ ) between patients with and without brain tumors. The direct cost of admission was significantly greater in patients with brain tumors $(\$ 15,755.80$ vs $\$ 9871.50$, p < 0.001 ), as was the rate of 30 -day readmission (20.6\% vs $2.4 \%, \mathrm{p}<0.001$; Table 8).

\section{Discussion}

Our results indicate that the risk associated with CSF shunting in patients with high-grade gliomas complicated by hydrocephalus is not insignificant. Two patients suffered ICHs after shunting, one of which was fatal. Three patients died during their admission, and 8 died within 30 days of shunting. The 30-day readmission rate was also fairly high in both our institutional cohort and among patients whose outcomes were reported to a national database. Revision surgery was necessary in a substantial proportion of patients, although the rate of revision surgery did not differ from that of a cohort of patients with NPH. Similarly to previous reports, our data suggest that shunting can effectively palliate the symptoms of hydrocephalus in this patient population. ${ }^{1}$ However, our results also suggest that the risks and benefits should be carefully considered prior to proceeding with shunting, particularly in patients with advanced disease.

Shunting was complicated by ICH in 2 of 4 patients who received bevacizumab prior to shunt insertion (Fig. 1). Spontaneous ICH is a known, though relatively uncommon, complication of bevacizumab therapy. ${ }^{4,7,13}$ We report a direct association between prior bevacizumab therapy and hemorrhage after shunting, which underscores the Food and Drug Administration's black box warning to avoid surgery of any kind within 28 days of bevacizumab infusion. The 2 patients who suffered a hemorrhage in our cohort last received bevacizumab 16 and 29 days before shunt placement. While these patients may have benefited from additional delay prior to shunting, the time from last bevacizumab dose after which the risks of shunt placement are acceptable remains an open question. Studies of bevacizumab pharmacokinetics have estimated an elimination half-life after systemic infusion of approximately 20 days. ${ }^{10,11}$ Of note, however, a recent study of patients with colorectal carcinoma found that bevacizumab was still detectable in serum 6 months after the last infusion. ${ }^{10}$ Moreover, given the delayed effects on wound healing seen after bevacizumab infusion, ${ }^{9}$ the effects of bevacizu-

TABLE 8. Comparison of institutional outcomes after shunt treatment for patients with and without primary brain tumors

\begin{tabular}{lccc}
\hline \multicolumn{1}{c}{ Outcome } & No Brain Tumor $(\mathrm{n}=4251)$ & Brain Tumor $(\mathrm{n}=112)$ & $\mathrm{p}$ Value \\
\hline Length of stay, mean (SD) & $3.5(1.6)$ & $6.9(4.8)$ & $<0.001$ \\
\hline Complication rate, mean \% (SD) & $2.8(4.4)$ & $6.7(23.0)$ & 0.054 \\
\hline Mortality rate, mean \% (SD) & $0.2(1.0)$ & $1.2(6.9)$ & 0.104 \\
\hline Direct cost of admission, mean (SD) & $\$ 9871.5(\$ 2849.3)$ & $\$ 15,755.8(\$ 8980.0)$ & $<0.001$ \\
\hline 30-day readmission, mean \% (SD) & $2.4(3.8)$ & $20.6(37.6)$ & $<0.001$ \\
\hline
\end{tabular}


mab persist after clearance from the systemic circulation. These effects may also become more pronounced with each subsequent surgery, ${ }^{2}$ which is of relevance to patients undergoing shunting after a prior craniotomy. In accordance with the Food and Drug Administration's recommendations, our current institutional policy is to proceed with shunting no sooner than 4 weeks after the most recent bevacizumab dose. Regardless, shunting in patients with prior bevacizumab exposure should be approached judiciously, and patients should be counseled on the significantly elevated risks in these instances.

Revision shunt surgery was necessary in $17.1 \%$ (7/41) of patients, with a rate of $21.2 \%$ (7/33) among patients who survived at least 30 days after initial shunt placement. Interestingly, in a comparison of patients with high-grade gliomas and those undergoing shunt treatment for NPH, the rates of revision surgery were similar between these 2 groups. It should be noted, however, that the mean time to revision among patients with NPH was greater than that of patients with gliomas (Table 6), and $43.0 \%$ of patients with NPH undergoing revision underwent reoperation after 150 days from initial surgery, which was the median time to death after shunting in the glioma cohort. The limited survival time among patients with gliomas may thus impede a comparative analysis of risk of shunt failure between this and other patient populations. Regardless, whether the risk is greater in patients with high-grade gliomas, the relatively high probability of requiring additional surgery, or simply subsequent readmission, should be considered in patients with limited life expectancy. Moreover, the markedly high rate of mortality within 30 days of shunting $(19.5 \%)$ observed in our study suggests that hydrocephalus may sometimes be a manifestation of end-stage disease for patients with malignant gliomas. This may be particularly true in patients with evidence of ependymal or leptomeningeal enhancement on MRI, a finding that we found to be associated with 30-day mortality. Leptomeningeal enhancement is a reliable indicator of tumoral CSF dissemination ${ }^{14}$ likely signifying limited potential for prolonged survival. Particular care should be taken when counseling patients and families regarding placement of a CSF shunt in this population.

\section{Limitations}

Our study is limited by the small number of patients in our institutional cohort, and it was likely underpowered to identify patient characteristics that are significantly associated with complications or revision surgery. In addition, the small sample size may have led to an overestimation of the risks of shunting in this patient population, as evidenced by the discrepancy between our in-hospital mortality rate $(7.3 \%)$ and that observed in the CDB/RM $(1.2 \%$; compare Tables 1 and 8). Larger studies will be needed to better characterize the risks of shunt placement in patients with high-grade gliomas complicated by hydrocephalus. A small but significant number of patients within this cohort had the proximal end of the shunt catheter placed in an enlarging resection cavity cyst, subdural, epidural, or subgaleal space as opposed to directly in the lateral ventricle. While these fluid collections were in communication with the lateral ventricle, the underlying pathophysiology in these cases may differ from traditional communicating hydrocephalus, potentially affecting the generalizability of our results to glioma patients receiving a standard ventricular shunt. Nevertheless, we feel that the pathology in these cases was ultimately due to impaired CSF resorption, and thus we included them in our cohort. Our analysis of outcomes contained within the national database is subject to limitations of the ICD-9 and -10 coding systems. While through the use of appropriate codes we were able to isolate patients with malignant primary brain tumors, it is possible that some patients included for analysis did not have glial-based tumors.

\section{Conclusions}

In the present study, we provide a measure of the risk of complications, need for revision surgery, and mortality after shunting in the setting of high-grade gliomas. While we confirm previous results that shunting can be effective in improving the symptoms of hydrocephalus in this patient population, our results indicate that patients should be selected carefully for this procedure.

\section{References}

1. Castro BA, Imber BS, Chen R, McDermott MW, Aghi MK: Ventriculoperitoneal shunting for glioblastoma: risk factors, indications, and efficacy. Neurosurgery 80:421-430, 2017

2. Clark AJ, Butowski NA, Chang SM, Prados MD, Clarke J, Polley MY, et al: Impact of bevacizumab chemotherapy on craniotomy wound healing. J Neurosurg 114:1609-1616, 2011

3. Fischer CM, Neidert MC, Péus D, Ulrich NH, Regli L, Krayenbühl N, et al: Hydrocephalus after resection and adjuvant radiochemotherapy in patients with glioblastoma. Clin Neurol Neurosurg 120:27-31, 2014

4. Fraum TJ, Kreisl TN, Sul J, Fine HA, Iwamoto FM: Ischemic stroke and intracranial hemorrhage in glioma patients on antiangiogenic therapy. J Neurooncol 105:281-289, 2011

5. Friedman HS, Prados MD, Wen PY, Mikkelsen T, Schiff D, Abrey LE, et al: Bevacizumab alone and in combination with irinotecan in recurrent glioblastoma. J Clin Oncol 27:47334740, 2009

6. Inamasu J, Nakamura Y, Saito R, Kuroshima Y, Mayanagi K, Orii M, et al: Postoperative communicating hydrocephalus in patients with supratentorial malignant glioma. Clin Neurol Neurosurg 106:9-15, 2003

7. Khasraw M, Holodny A, Goldlust SA, DeAngelis LM: Intracranial hemorrhage in patients with cancer treated with bevacizumab: the Memorial Sloan-Kettering experience. Ann Oncol 23:458-463, 2012

8. Kreisl TN, Kim L, Moore K, Duic P, Royce C, Stroud I, et al: Phase II trial of single-agent bevacizumab followed by bevacizumab plus irinotecan at tumor progression in recurrent glioblastoma. J Clin Oncol 27:740-745, 2009

9. Ladha H, Pawar T, Gilbert MR, Mandel J, O-Brien B, Conrad $\mathrm{C}$, et al: Wound healing complications in brain tumor patients on Bevacizumab. J Neurooncol 124:501-506, 2015

10. Li J, Gupta M, Jin D, Xin Y, Visich J, Allison DE: Characterization of the long-term pharmacokinetics of bevacizumab following last dose in patients with resected stage II and III carcinoma of the colon. Cancer Chemother Pharmacol 71:575-580, 2013

11. Lu JF, Bruno R, Eppler S, Novotny W, Lum B, Gaudreault J: Clinical pharmacokinetics of bevacizumab in patients with solid tumors. Cancer Chemother Pharmacol 62:779-786, 2008

12. Montano N, D'Alessandris QG, Bianchi F, Lauretti L, Doglietto F, Fernandez E, et al: Communicating 
hydrocephalus following surgery and adjuvant radiochemotherapy for glioblastoma. J Neurosurg 115:11261130, 2011

13. Nishimura T, Furihata M, Kubo H, Tani M, Agawa S, Setoyama R, et al: Intracranial hemorrhage in patients treated with bevacizumab: report of two cases. World J Gastroenterol 17:4440-4444, 2011

14. Onda K, Tanaka R, Takahashi H, Takeda N, Ikuta F: Symptomatic cerebrospinal fluid dissemination of cerebral glioblastoma. Computed tomographic findings in 11 cases. Neuroradiology 32:146-150, 1990

15. Roth J, Constantini S, Blumenthal DT, Ram Z: The value of ventriculo-peritoneal shunting in patients with glioblastoma multiforme and ventriculomegaly. Acta Neurochir (Wien) 150:41-47, 2008

16. Stupp R, Mason WP, van den Bent MJ, Weller M, Fisher B, Taphoorn MJ, et al: Radiotherapy plus concomitant and adjuvant temozolomide for glioblastoma. $\mathbf{N}$ Engl J Med 352:987-996, 2005

17. Wen PY, Macdonald DR, Reardon DA, Cloughesy TF, Sorensen AG, Galanis E, et al: Updated response assessment criteria for high-grade gliomas: response assessment in neuro-oncology working group. J Clin Oncol 28:1963-1972, 2010

\section{Disclosures}

Dr. Lanzino: consultant for Medtronic.

\section{Author Contributions}

Conception and design: all authors. Acquisition of data: Rinaldo. Analysis and interpretation of data: all authors. Drafting the article: Rinaldo, Brown. Critically revising the article: all authors. Reviewed submitted version of manuscript: all authors. Approved the final version of the manuscript on behalf of all authors: Parney. Statistical analysis: Rinaldo.

\section{Correspondence}

Ian F. Parney, Department of Neurological Surgery, Mayo Clinic, 200 First Ave. SW, Rochester, MN 55905. email: parney.ian@ mayo.edu. 